\title{
Acknowledgments to the members of the Editorial Board
}

\author{
Gabriele Kaiser
}

(c) FIZ Karlsruhe 2010

The term of the Editorial Board of the ZDM has expired after 3 years, by the end 2009. Within these 3 years, the members of the Editorial Board have worked intensively on the journal and they have developed the ZDM into an internationally recognised journal. Hence, I would like to express my gratitude to all members of the Editorial Board for their support. Two new members will be part of the new Editorial Board, which will start working in issue 1, 2010.
Thus, I would like to welcome Marcelo C. Borba, Sao Paulo State University at Rio Claro, Brazil and Berinderjeet Kaur, National Institute of Education, Singapore, to the Editorial Board. I would especially like to thank the resigning members Rudolf Sträßer and Edith Schneider. I look forward to working with the new editorial board for the next 3 years.

G. Kaiser $(\square)$

Didactics of Mathematics, Faculty of Education,

University of Hamburg, Von-Melle-Park 8,

20146 Hamburg, Germany

e-mail: gabriele.kaiser@uni-hamburg.de 